\title{
Subsidiarity in Environmental Issues: Nuances and Shifts
}

\section{Florencio R. Riguera}

The Catholic University of America, Washington, D.C.

\section{Abstract}

Although subsidiarity is dipolar, preference has been for the "lower" pole at the early stages of its development as a principle in Quadragesimo Anno: the "higher" administrative unit should act only if the "lower" unit could not deal with the issue. But in a generation, Pacem in Terris posited a nuance that put the preference on the "higher" unit. The capabilities of "higher" units could supersede the rights of "lower" units because the "on reserve" aid from "higher" units leads to more effectivity. Then, applying integral ecology, Laudato Si' put the preference on the "higher" pole when issues are environmental in character. This stems from an understanding of complex and interconnected mechanisms in the interaction between populations and the environment. Because Nature has predetermined ways of acting and reacting to events like those caused by populations, Nature relays the impact of actions, such as environmental backlash, to other locations, sections, or later generations; it can also "slap back" at the local agents of events. Thus, the default option should be for the "higher" units to act when it comes to researching the complex interconnections of actions at the ecological level. But this option can lead to gaming the deliberations on public policy with questions of uncertainty or risk because valid understanding is needed to guide actions or policies. Perspectives broader than the local in terms of understanding and of values to be shared are needed.

Keywords: subsidiarity, ecology, interconnectedness, roles, responsibility, social organization

\section{Introduction}

The principle of subsidiarity pertains to the organization of society: it defines the relationship between social units based on their level or scope of competence to act on a given situation. Thus, it revolves around status-roles and it is dipolar because of its higher-lower framework ${ }^{1}$. The weight of emphasis or focus can move closer to

\footnotetext{
${ }^{1}$ For convenience, "lower" refers to the social unit that has "narrower" scope of competence or authority, such as, the local (relative to the regional or national) or the national (relative to the global).
} 
either of its poles in terms of which social unit should act on the situation at hand. Designating which social unit (pole) should act on a given situation is contingent on certain considerations. And these entail focusing on certain facets of the situation in relation to the social units or actors. It is in this context of higher-lower and the default-conditional that I explore nuances of subsidiarity and corresponding shifts in the designation of the default social unit: the higher or lower social unit. The underlying point is the criterion to use in shifting the weight or default position closer to one or the other pole. Further, the criterion is premised on the well-being of the social actors as they understand and valorize it vis-à-vis a situation requiring their action.

I trace the significant shifts in the understanding or application of the principle and construe the underlying nuances in the Catholic social teachings. The aim is to understand how subsidiarity is related to other concerns like those involving the environment and how shades of meaning or points of emphasis can lead to courses of action. As a principle of social organization, subsidiarity is not characteristically Catholic; but because of the contributions of the Catholic Church to its development, it would be helpful to be aware of the concerns that shaped the facets of emphasis and the corresponding realignments in its application.

\section{Major Shifts}

Subsidiarity is one of the basic principles in the Catholic social teachings. Pius XI developed it in Quadragesimo Anno (1931). Pius XI put forth his concerns: "Just as it is gravely wrong to take from individuals what they can accomplish by their own initiative and industry and give it to the community, so also it is an injustice and at the same time a grave evil and disturbance of right order to assign to a greater and higher association what lesser and subordinate organizations can do;" (Quadragesimo Anno, \#79); and "as occasion requires and necessity demands," the State should concentrate on the higher or broader task of, among others, directing lower units lest its efforts get dissipated and detract from the effectiveness of its functioning (\#80). The higher unit, the State, has the responsibility of helping individuals or lower units contribute to society but it must "never destroy and absorb" the latter (\#79). Here, the State's assistance to the lower units or individuals is "on reserve"; conditionality has been built into the principle. Reading between the lines, we can sense another set of concerns or nuances: (a) the lower social unit is competent to act on the situation, more specifically, in terms of understanding it and in conforming the action, or the solution to be crafted, to local values or ethos; (b) action by the lower unit would be more effective in dealing with the situation because of the guidance of local knowledge and values. Here, the lower social unit is the preferred pole to act on the situation - it is the "default position".

Emphasis on the lower unit was predicated also on the inherent worth and dignity of the individual person. At the time, the encyclical opposed the socialism that was taking shape. Specifically, the point was not to allow individuals to be "sacrificed" for 
the sake of the collectivity. Pius XI devoted several paragraphs in Quadragesimo Anno arguing against the sort of collectivism that would "employ the most violent means" to bring about "fierce class struggle" and to abolish private property (\#112). The value of community is paramount in Christianity, notably since the Apostolic era: the way the community of the early Christians lived gives an illustration par excellence. They sold their possessions - lands or houses -- and the Apostles distributed the proceeds according to each one's needs; no one was in need (The Acts of the Apostles, $4: 32-35)^{1}$. The relation and the impact of the social whole to its constituents in one era are different than those in the other. The social contexts and the contrast between these ways of viewing society would lead one to appreciate the stance that favors the lower unit as the "default position"2.

\section{Competence: Toward the Higher Pole}

Then the first major shift occurred in 1963. In Pacem in Terris John XXIII shifted the "default position" towards the higher social unit. Competence and effectiveness of the action to be taken were given more weight than they were given earlier when the scale of social relations was narrower. But the global scope and scale of the situation appear to have contributed to this shift: the encyclical recognized that there were situations or "problems [that could be] considered too difficult for the rulers of individual States to solve with any degree of success," (Pacem in Terris, \#140). At least, the importance of competence assumed a nuance of greater importance. The unit that could act in a global scope was more competent than individual States; the resources at its disposal would contribute to its higher competence. Vis-a-vis the closeness of the lower unit to the situation, the effectiveness of action was predicated also on the competence of the unit that would take action. The nuance is a matter of emphasis because understanding the problems adequately is (or, should be) integral to the task of designing solutions. Admittedly, it can be more challenging to tailor solutions to national or local values. Social identity can easily come to mind as a point of concern at this point. But Pacem in Terris made it clear that "it is no part of the duty of universal authority to limit the sphere of action of the public authority of individual States, or to arrogate any of their functions to itself," (\#141). It reiterated Quadragesimo Anno, but it recognized that calibrating the problem in terms of scope or scale prompted the shift of weight toward the higher social unit as the "default position".

Within a generation, therefore, there was a reframing of the concerns or the facts of the situation. In effect, Pacem in Terris introduced the situation itself, the object of action to be taken, as a factor to consider in the task of designating the "default position". This latter frame was broader or deeper because the definition of roles would not be limited to the relation between social units only; rather, the objective

\footnotetext{
${ }^{1}$ Revised Standard Version, Catholic Edition.

2 O'Brien and Shannon (1977) note that the social context was also a factor in some differences "in tone and general direction" between Leo XIII's Rerum Novarum and Pius XI's Quadragesimo Anno. Renewing the Earth, p 36.
} 
empirical situation was explicitly taken into account. Unpacking this point shows that the empirical situation is relevant to evaluating the effectiveness of the action to be taken. Further, the objective situation should matter in identifying the occasions wherein the State would appropriately extend help to lower units - as enunciated in Quadragesimo Anno. Therefore, Pacem in Terris revised Quadragesimo Anno in terms of the "default position" precisely by reframing the way status-roles should be defined between the social units. The revision derived from focusing on the outcome of action more than on who would perform action. In effect, the application of the subsidiarity principle was made contingent on the nature of the empirical situation toward which the action of social units would be directed. The competence of a social unit was relative also to the situation.

\section{The Environment's Role}

The next significant shift came with the employment of integral ecology approach in Laudato Si' of Francis I in 2015. Again, the shift is in terms of the point of emphasis and in the framing the action-situation relationship, rather than in terms of which pole should be the "default position". The nuance derives from an even more comprehensive perspective on the relationship between society and the environment. The basic views entail: (a) the objective empirical situation involves the workings of Nature, (b) these workings are determinate, meaning that Nature has its own way of "acting and reacting" to events or changes engendered by individuals or groups that constitute society. ${ }^{1}$

Further detailing out the way Nature works or reacts, the environment is understood and valorized in terms of (1) the resources it provides to populations or communities, (2) the way and pace in which it processes or recycles waste resulting from people's activities, the so-called "sink" function (Organisation for Economic Cooperation and Development, 2005).2 The interaction between societies and the environment is mediated by the tool of technology: technology can improve or worsen people's ways of accessing and transforming resources as well as ways of processing waste. These points come from science; and theological viewpoints can build upon them - as Laudato Si' does. And because of what science understands at present, the conceptual impact on the principle of subsidiarity is viewed in relation to further calibrating or nuancing the role of the empirical situation in the designation of which social unit is the "default position". Simply put, the environment matters a great deal. Laudato Si' offers an "approach to ecology which respects our unique place as human beings in this world and our relationship to our surroundings" (\#15). This means that the point of concern now is primarily how to comport with Nature's predetermined way of "acting and reacting" to people's activities and their outcome. Ultimately, comporting

\footnotetext{
${ }^{1}$ Society is viewed as an organized population; status-roles pertain to social organization.

2 The United Nations' list includes other functions in a finer way, but I submit that these two functions are the basic ones. This can be seen if land is considered as a resource the way air, water, and food are considered resources. The OECD refers to: United Nations (1997). Glossary of Environment Statistics, Studies in Methods, Series F, No. 67, \#7.31 and \#7.35.
} 
with the way the environment behaves is relevant to the well-being of peoples. This means that respecting the environment has utility to humans.

As regards the role of the environment, Paul VI wrote the first papal document that explicitly recognized environmental pollution as a social problem (Octogesima Adveniens, 1971: \#21). John Paul II's Sollicitudo Rei Socialis (1987, \#34) addressed development efforts and declared the need to respect the nature of things, to acknowledge the risk of depleting the environment's resources and to beware of health hazards ensuing from pollution. Speaking of subsidiarity in 1991, Centesimus Annus stressed the responsibility of the State (the higher unit) to create "favorable conditions for the full exercise of economic activity which lead to abundant opportunities for employment and sources of wealth" (\#15), the "favorability of conditions" would have included the ecological dimension. It also reiterated that the higher unit must support the lower unit "in case of need" and "help to coordinate [the activity of the lower unit] with the activities of the rest of society" (\#48). Now, Laudato Si' enunciates the same views. What distinguishes it is its explicitness in using environmental conditions as an integral facet of its principles of reflection and judgment - let alone the fact that the encyclical takes the human-environment relationship itself as its topic. As the scientific community and advocacy groups elaborated on the ecological perspective, Catholic social doctrine broadened and deepened its view of the environment.

\section{Ecological Complexity and Interconnectedness}

What stand out in an ecology-guided perspective are (a) the interconnectedness of events, actions, or their outcome: thus, people eventually need to cope with situations that they had engendered, (b) the complexity of the processes or mechanisms through which Nature "slaps back" at people, perhaps, at those who caused a change in the environment. Parsing out this list should show that the environment can relay the impact of some people's actions to other people (or communities in other locations (e.g., it can be a vector of pollution downstream); it can transmit the impact to later generations (e.g., toxic substances in the air, water, or soil that can cause diseases many years later). Viewed this way, the environment acts as a medium in the interaction between individuals or populations. People's actions have an objective impact that may be transboundary, transgenerational, or both. Laudato Si' advocates for "the conviction that everything in the world is connected" (\#16). In this context, it comes through even more cogently that the definition of status-roles must not disregard the role of the environment but rather, explicitly factor it in. And the facet of the situation that needs to receive attention is environmental backlash along with appropriate resource use. The threat of resource depletion is basically related to overharvesting, and that of environmental pollution is related to the overloading of Nature's capacity to process and recycle waste. Sustainability is viewed in terms both of the "resource function" and of the "sink function" of the environment. A case in point is health for people near or far, now or later: epidemiology shows the basic 
points of interconnectedness and complexity in the interaction between societies and the environment.

The basic notions have become clear from science. A few works depict the relationship or interaction between populations and the environment; they explain what an ecological approach looks into. Silent Spring (Carson, 1962), The Closing Circle (Commoner, 1971), and The Butterfly Defect (Goldin \& Mariathasan, 2014) focus more on the overloading of the "sink function". They also show the impact of technology and socio-political systems on situations in the environment. Human Ecology (Hawley, 1986), Governing the Commons (Ostrom, 1990) devote more time to the harvesting of resources. The environmental summits/conferences in Sweden (1972), Rio (1991), Johannesburg (2000), among others, employed this approach. The Montreal Protocol (1987) concentrated on phasing out the production and consumption of ozone-depleting substances that damaged the stratospheric ozone layer. The Kyoto Protocol (1997) and the Bali Protocol (2007), which is linked to the United Nations Framework Convention on Climate Change, aimed at reducing emissions on an international scale. The Paris Agreement (2015) took on the emblematic issue of climate change. The perspective is guided by an understanding of how everything in the environment is interconnected. What is important for the present purpose is to appreciate the nuance that further strengthens the preference for the higher social unit as the "default position". Further, the facet of the situation that gives cogency and urgency is that of environmental backlash. It is also helpful to recall that social, economic, or political systems play a role in the transmission of impact to certain sectors of the globe, "our common home", as Laudato Si' puts it -even as some of the harmful outcomes disproportionately afflict some sectors of society more than others. The encyclical has special concern for the poor (\#13).

\section{Toward an Ecology-Driven Subsidiarity}

Given now our understanding of how the environment has pre-determined ways of throwing back harmful impact to human and other life groups, the task of directing that Quadragesimo Anno accorded to the high-unit State accordingly acquires an ecological nuance. This nuance should smoothly lead to holding the whole, that is the higher unit, namely, the social, the global, as the preferred pole when it comes to determining what actions conform to the environment. The reasons for this view are intertwined with one another. Given the complexity and interconnectedness in an ecosystem (climate change being the emblematic case), acquiring an adequate and valid understanding of the mutual or interactive impact in the human-environment relationship would require more resources and competencies than merely acquiring knowledge at the lower or local level. Because of this, relatively large-scale research activities should appropriately be undertaken by the higher units. The Intergovernmental Panel on Climate Change (IPCC) under the auspices of the United Nations is an illustrative case, even as private or non-international groups can also conduct studies of the same scope and scale. The idea is not new at all: global-scale 
studies simply augment in substance and scale the Environmental Impact Assessment (EIA) which came into use decades ago for purposes of policy-making or project planning. The way the "whole" or the "common" is defined would invite policymaking participants to identify who would be benefited/harmed by the common good/harm. Being able to identify who can enjoy public goods, like the climate, and who can be hurt by "public harms" (like climate, as well!) can facilitate the development of solidarity with "others with a face" today - or perhaps foster GoldenRule sentiments toward others, including those yet to be born ${ }^{1}$ Laudato Si' (\#196) urges solidarity with others, especially with the less fortunate, in "our common home".

In addition, "[s]ociety as a whole, and the state in particular, are obliged to defend and promote the common good." (\#157). And subsidiarity grants freedom to develop the capabilities present at every level of society. It also demands "a greater sense of responsibility for the common good from those who wield greater power," (Laudato Si', \#196; emphasis added). Considering the complex interconnectedness that makes the environment act as a vector of the impact of actions or events, designating which social unit is preferred to take action on demands that the lower units take into consideration the well-being of the whole. Action understood narrowly can harm the whole. This is because of the pre-determined way Nature "acts and reacts": it transmits harmful effects of actions to others (Carson, 1962; Commoner, 1971; Goldin $\&$ Mariathasan, 2014). It follows that it is the lower social units (or individuals) who must align with common-good values. More explicitly, the frame of analysis in policy deliberation, adoption, and implementation should include as a criterion the wellbeing of populations in other locations and, again, of future generations. The point here is that people might not be readily aware of the impact of their actions; nevertheless, the environment does transmit the impact to other people. And in this context, J. S. Mill's idea would apply: "as soon a person's conduct affects prejudicially the interests of others, society has jurisdiction over it".2: As regards differing stances which may be associated with differences in culture, religion, level and type of education, Confucius offers a helpful idea: in terms of nature, peoples are very much alike; in terms of habits [culture], they are very different (The Analects, 17:2). ${ }^{3}$ Health is a condition that is better viewed and understood as something of nature rather than one of habit, which may be culture-bound. Health would be valued similarly across cultures on the same planet.

Things environmental are clearly in the "nature" category. And because of the practically autonomous way Nature bounces back -- or relays -the impact of actions

\footnotetext{
${ }^{1}$ The negative formulation of the Rule from Confucius (孔子) might be easier to grasp because of the need to give due attention that the harm of environmental pollution: “己所不欲, 勿施於人”, 論語 (The Analects), 15:24 ("Do not do to others what you do not want to be done to you.").

${ }^{2}$ Quoted from On Liberty in Lemert (2017), p. 55.

3 “性相近也, 習相遠也”, 論語 (The Analects), 17:2 (The rendition in the main body of the text is mine.)
} 
to people, the "victims" do not have any choice: they just absorb the impact. For example, people downstream simply "accept" what has been dumped upstream; communities in deforested areas simply live with the risk of mudslides. By contrast, people dealing with actions or practices that have no significant environmental impact have the choice of adopting or not adopting a certain practice - e.g., childrearing practices. In these cases, the environment does not just dump the impact on other populations. Therefore, when it comes to dealing with issues with significant environmental impact, guiding and harmonizing the direction of development efforts is part of the higher units' task of directing. Accordingly, research that guides policies or practices - and the task of directing the whole, which is governance itself -- would also be assigned to the higher units by default. The task of valorizing economic versus ecological benefits would need to be critically appraised: who or which social units would be benefited or harmed? What about the well-being of future generations? Having the perspective formulated by the higher units is the wiser choice.

It is here that the principle of solidarity comes in: who are the ones we hold ourselves to be "in solidarity with" when we identify the beneficiaries or victims of empirical conditions that would result from our actions? If and when the environment relays the impact of actions to other populations, the common good is, in effect, subject to pre-determined opportunities and constraints that derive from the empirical conditions. Therefore, the tie between the common good and sentiments of solidarity is an integral factor in designating the "default position". The Compendium of the Social Doctrine of the Church (2004) speaks of interdependence among people and links solidarity to the effectuation or enhancement of the common good. With a more nuanced ecological framework, giving explicit attention to the mitigation or minimization of the harm bounced back by the environment to human populations should be a dimension of the principle of solidarity and that of the common good. And, by designating status-roles, subsidiarity aims at fostering actions, practices, or policies that comport with the environment.

\section{Subsidiarity in Context}

As previously noted, because of its ability to bounce back or relay impact to other parts of the whole, Nature demands that it be explicitly included in the definition of the roles social units or individuals. This means that the social definition of roles, and the use of "whose rights/responsibilities" as the primary rubric would have to give way to the substantive question of how individuals or communities should interact with an adequate understanding of the way Nature behaves. Conceptualizing and applying subsidiarity requires that the first step should be to recognize the "what" and the "how" that comport with Nature. What actions, practices, and policies would mesh with Nature's way? How are these to be carried out? Only later, should the "who" -- the higher or the lower social unit - be designated. The formulation of the principle of subsidiarity can give the impression that the primary concern is the "who". The sovereignty of states can be an issue (Colombo, 2012; Jasanoff, 2013; 
Carozza, 2016) just as local autonomy and identity can be invoked. But a careful reading between the lines unpacks the primacy of considering the "what" and the "how" when actions or practices are understood to have a non-negligible environmental impact. Put differently, what comports with the common good (or, the whole, is the "more effective" solution; and, therefore, the task of designating who should act the situation comes only later. When it comes to environmental issues, the "default position" should be the higher unit. Here, ecology trumps subsidiarity; it logically precedes and guides the application of subsidiarity. The approach is what would now be familiar to many: 'think globally; act locally - go glocal!'

The big picture of nuances and shifts appears as follows: with reference to time of Quadragesimo Anno, developments have shifted the weight closer to the higher pole because of the circumstances. Now we recognize the role of the environment, specifically as the object of humans' actions and as a medium or transmitter of impact to others. The elements that this framework nuances are: (a) the ability of the social unit also takes into account the empirical situation, and (b) the "occasion" or "necessity" now need an ecologically guided nuance. With reference to Pacem in Terris, the competence of a social unit should not be limited to the scope of its power nor to the amount of its resources: these have to be calibrated by the environmental situation. With reference to Laudato Si' the understanding of who, or which groups, stand to benefit from "the common good" or be harmed by "communal hazards" again, both through the environment - is of paramount importance. Adopting and employing an ecological perspective shaped and impelled the shifts toward the higher social unit as the "default position"..

\section{Social Epistemology}

The application of subsidiarity in the relations among states or regions highlight the importance of social epistemology. Communication or dialogue is very important because of the need for member states (or constituent parts) to understand how the actions, practices, or policies that they could execute on their own might impose foreseeable impact or risk on other members. The logic derives from the same ecologically complex interconnectedness.

Determining what practices or policies would comply with "Nature's demands" and what would not is basically a matter of social epistemology: what knowledge the participants or stakeholders accept as "correct knowledge", and thus, usable to guide action or policy-making? The question becomes subject to what is socially constructed as "valid", if not "the correct knowledge". The sciences have the rigor and capability to demonstrate their findings and analysis. And constituents or stakeholders need to communicate with one another to harmonize their actions or policies. Nevertheless, scientists have faced arguments of different sorts. Power has a role to play in the process of social construction (Jasanoff, 2013). Benedict XVI appealed for particular interest to align to the common good - and he did so by explicitly invoking the principle of subsidiarity: "In accordance with the principle of 
subsidiarity it is important for everyone to be committed at his or her proper level, working to overcome the prevalence of particular interests.". ${ }^{1}$ Michaels (2008) also warns of the insidious tactic of invoking uncertainty or doubt when it comes to dealing with legislation on economic activity. Doubt or uncertainty is built into the method of the sciences: absence of empirical evidence makes an assertion or claim questionable; the margin of error might be too high vis-à-vis the measure of restricting the exercise of people's rights to pursue an economic activity. Attribution of causality to human activities can be appropriately debated, and so can the projection of future conditions be questioned. The strategy of employing doubt in policy debates and deliberations presents a veritable challenge. The onus of proof lies on the side of the advocates, and the "doubters" have the easier task. Intractable debates can stymy efforts at crafting solutions and eventually the stakeholders end up eluding the responsibility of conforming actions or practices to environmental constraints.

Michaels' caveat leads to two basic points: (a) the craft of lawmaking and interpretation, and (b) the precautionary principle. The first point is about how laws are enacted. Lobbies and social movement campaigns advocate for policy or legislation options. They practically make claims on "what ought to be" as to be legally enforced. Here, if the environment is not given the respect it would in an ecologyguided approach, it is likely that laws or policies would be practically limited to the criteria of rights. In contrast, "Nature's predetermined way" of acting/reacting is closer to obligations than to people's rights to act in a particular way. Hence, the ecology is something to comport with; populations can only temporarily disregard "Nature's predetermined way" with impunity because environmental backlash is bound to bounce back to people later. Needless to say, infusing an ecological perspective into lawmaking or interpretation is a huge task, even as viewing its need in the abstract can appear to be very simple and easy. Beyond "merely hoping", there is a notion that can serve as a premise: Posner (2015) claims that "the outcomes of constitutional cases are not driven by legal jargon but by the justices' ideological views and rough balancing of the costs and benefits of alternative outcomes" (p. 138). The ecology should be a criterion for "costs and benefits" of very palpable outcomes of actions or activities that are recognized as within the rights of citizens or corporations to undertake. Carozza (2016, p. 66) identifies the environment as a discrete functional area of international law where the development of principles should continue - given what he observes as "fragmentation". The cogency of arguments based on the complex interconnectedness of the ecology can provide a unifying motif to this effort.

Here, we can invoke the precautionary principle, which does not operate in a vacuum because previous experience contributes to the molding of a precautionary attitude. For this reason, precaution is itself shaped by the "empirical evidence" in earlier

\footnotetext{
1 "Message for the Celebration of the World Day of Peace", \#11; italics in the original.
} 
observations. Absent convincing proof of, say, causal attribution in cases of pollution or epidemiology, the pedestrian approach of "erring on the conservative side" can be employed. In the meantime, the best that science can provide is (or, should be) the "compelling guide". There is no reasonable alternative. The issue here is one of prudence; it goes beyond the scope empirical knowledge alone. Gaming the lawmaking system in such a way as to limit deliberations to issues of, say, economic rights -- to the exclusion of ecological values and sensibility -- is definitely an option. But what consequences will which population sectors face in other locations or in some future time?

These challenges lead us back to the more basic point of determining the "what/how" of actions before designating "who" acts on a given situation. The point is not that "lower units" invariably evaluate alternatives for action in a "narrow" or particular fashion. Rather, ceteris paribus, there is more risk for letting particular interests lead to harm for the larger whole if the "who" ("whose rights") is the first criterion. And, therefore, when dealing with issues that entail the ecology, the "who" must be substantively guided by the "what" and the "how".

\section{Shifts within the Whole}

The shifts in terms of emphasis on the unit were made in the context of the whole. And to the extent that the higher unit has broader responsibilities for the whole, the current point of emphasis is the higher unit. The way the environment as a critical component of the common good has been appreciated is a factor in this shift. The lower units retain their "default position" when it comes to issues "farther" from the category of "environmental" issues, like actions or practices concerning units like the family, or, matters pertaining local identity, as has been pointed out already. The point is simple: if or when the environment does not autonomously transmit harm to other populations, the lower unit would be preferred to take action on the situation.

One facet of the stipulation of subsidiarity deals with the relationship between the rights and autonomy of one social unit and those of another. And the conditionality that is integral to the principle postulates the need to balance the interests of the lower units with those of the higher units. The common good serves as the guiding value in this balancing. Therefore, emphasizing potential conflicts between the interests of the units - as in autonomy versus centralization - can be misleading if organizational structures are assessed without reference to the well-being of the whole. After all, lower units or individuals are what constitute the whole; the common good is oriented to fostering, nurturing, or supporting the well-being of lower units or individuals. Consequently, framing the relationship and interaction between lower units and higher units demands an explicit recognition of the way the actions of lower units impact the whole. The environmental dimension of actions within a population illustrate how this impact-relay transpires in the concrete with immediate or eventual palpable outcome. 


\section{Conclusion}

Science today shows more clearly that the environment is a basic and critical component of the common good. Therefore, societies - and the individuals and groups comprising them - need to conform their actions or practices to the environment's pre-determined way of "acting and reacting" to changes or conditions brought about by these actions or practices. In this frame of understanding, what needs to be considered first is the how the actions or practices comport to the environment. Eventually, what comports with the environment is beneficial to humans. It follows that if the approach is ecology-guided, the designation of roles in terms of who acts first on a given situation is relegated to a secondary level of consideration. In other categories of situations, where the impact of actions or practices are relatively contained in a "narrower" scale, the earlier designation that the lower social unit acts first, is the better option. The invocation or application of the principle of subsidiarity is contingent on the substantive area where actions and practices are carried out. And, because the identification of "outside victims" of actions or practices entails an understanding of how the environment relays the impact in time and place, the principle of solidarity is also secondary to the principle of the common good.

Social epistemology assumes an important role because it is the only way through which different populations on the planet can align their actions or activities to the constraints that the ecology imposes. Solidarity with others and commitment to the common good both highlight the importance of good will. And both good will and scientific knowledge should guide the application of subsidiarity because designating roles in matters environmental must take the objective impact of actions or practices into account.

\section{References}

[1] Benedict XVI (2010), "Message for the Celebration of the World Day of Peace", http://w2.vatican.va/content/benedictxvi/en/messages/peace/documents/hf_ben-xvi_mes_20091208_xliii-worldday-peace.html [Accessed 2018 June 14].

[2] Cahill, Maria (2016). "Sovereignty, Liberalism and the Intelligibility of Attraction to Subsidiarity", The American Journal of Jurisprudence, Vol. 61, No. 1, pp. 109-132.

[3] Carozza, Paolo (2016). "The Problematic Applicability of Subsidiarity to International Law and Institutions", The American Journal of Jurisprudence, Vol. 61, No. 1, pp. 51-67.

[4] Carson, Rachel (1962). Silent Spring, Houghton Mifflin.

[5] Colombo, Alessandro, (Editor) (2012). Subsidiarity and Governance, Palgrave Macmillan. 
[6] Commoner, Barry (1971). The Closing Circle, Bantam Book.

[7] Francis I (2015). Laudato Si'. Encyclical Letter.

[8] Goldin, Ian \& Mariathasan, Mike (2014). The Butterfly Defect, Princeton University Press.

[9] Hawley, Amos H. (1986). Human Ecology: A Theoretical Essay, University of Chicago Press.

[10] Jasanoff, Sheila (2013). "Epistemic Subsidiarity - Coexistence, Cosmopolitanism, Constitutionalism", The European Journal of Risk Regulation, No. 2, pp. 133-141.

[11] John Paul II (1987). Sollicitudo Rei Socalis. Encyclical Letter.

[12] John Paul II (1991). Centesimus Annus . Encyclical Letter.

[13] John XXIII (1963). Pacem in Terris. Encyclical Letter.

[14] Lemert, Charles (Editor) (2017). Social Theory, 6 th $^{\text {th }}$ dition, Westview Press.

[15] Michaels, David (2008). Doubt Is Their Product, Oxford University Press.

[16] O'Brien, David J. and Shannon, Thomas A., (Editors) (1977). Renewing the Earth, Image Books.

[17] Organisation for Economic Cooperation and Development [OECD] (2005). (https://stats.oecd.org/glossary/detail.asp?ID=6424 (Accessed 20180620)

[18] Ostrom, Elinor (1990). Governing the Commons, Cambridge University Press.

[19] Paul VI (1971). Octogesima Adveniens. Letter in commemoration of the 80th anniversary of Rerum Novarum (encyclical of Leo XIII).

[20] Pius XI (1931). Quadragesimo Anno. Encyclical Letter.

[21] Pontifical Council for Justice and Peace (2004). Compendium of the Social Doctrine of the Church. Vatican City.

[22] Posner, Richard A (2015). Review essay on The Court and the World in Foreign Affairs, Vol. 94, No. 6 (Nov-Dec), pp. 138-141. 